\title{
Timing of Adjuvant Chemotherapy in Colorectal Cancer Patients
}

\author{
Moo-Jun Baek \\ Department of Surgery, Soonchunhyang University College of Medicine, Cheonan, Korea
}

\section{See Article on Page 151-155}

Currently, adjuvant chemotherapy has an important position as a treatment for stage III colorectal cancer. In Korea, it is a matter of fact that certain standardized treatments are given in the chemotherapy after colorectal cancer surgery. Though it is supposed generally that adjuvant chemotherapy should be initiated within 8 weeks after surgery, some physicians claim that earlier initiation of chemotherapy has a better influence on the prognosis [1]. In that sense, the article published in the current issue of the Annals of Coloproctology [2] has a considerably significant meaning. The authors carried out this retrospective study with many patients by dividing them into three groups based on the time points for the initiation of their chemotherapy. The authors' conclusion is that there are no differences in the patients' overall survival rate and relapse-free survival rate due to the time points of their chemotherapy. Thus, the authors recommend that patients who may experience complications after surgery receive chemotherapy after a having sufficient recovery time without hasting adjuvant therapy.

In fact, for colorectal cancer surgeons, a sufficient period of recovery after surgery is very significant. Especially, in cases where the patients' conditions are poor, having a considerably long period of recovery is an important factor in preventing and treating complications due to chemotherapy. However, there are actually cases where chemotherapy is initiated very early due to the patients' request or the doctors' expectation that earlier initiation of chemotherapy may have more of an influence on the patients' prognosis. Showing that there are no great changes in patients' prognoses due to the time points for the initiation of chemother-

Correspondence to: Moo-Jun Baek, M.D.

Department of Surgery, Soonchunhyang University Cheonan Hospital, Soonchunhyang University College of Medicine, 31 Suncheonhyang 6-gil, Dongnam-gu, Cheonan 330-930, Korea

Tel: +82-41-570-3633, Fax: +82-41-571-0129

E-mail: ssurge@sch.ac.kr

(C) 2013 The Korean Society of Coloproctology

This is an open-access article distributed under the terms of the Creative Commons Attribution NonCommercial License (http://creativecommons.org/licenses/by-nc/3.0) which permits unrestricted noncommercial use, distribution, and reproduction in any medium, provided the original work is properly cited. apy, the authors' conclusively suggest a good theoretical backgrounds, based on which patients who may experience complications due to chemotherapy, should not be pushed to undergo chemotherapy hastily.

\section{REFERENCES}

1. Des Guetz G, Nicolas P, Perret GY, Morere JF, Uzzan B. Does delaying adjuvant chemotherapy after curative surgery for colorectal cancer impair survival? A meta-analysis. Eur J Cancer 2010;46: 1049-55.

2. Kang KM, Hong KS, Noh GT, Oh BY, Chung SS, Lee RA, et al. Optimal time of initiating adjuvant chemotherapy after curative surgery in colorectal cancer patients. Ann Coloproctol 2013;29: 151-5. 